\title{
Por que educação sem escola?
}

Tascieli Feltrin ${ }^{1}$

Fernanda Monteiro Rigue ${ }^{2}$

Guilherme Carlos Corrêa ${ }^{3}$

\section{Resumo}

Este artigo realiza uma revisão bibliográfica consultando autores e críticos dos processos de escolarização e polarização da educação das massas pelo Estado, tais como: Illich, Proudhon, Reimer e Godwin. Apresenta uma reflexão sobre possíveis efeitos sociais da desescolarização da educação e problematiza o tratamento dado à educação e ao ensino escolar potencializando as possibilidades de pensar educação para além da escolarização. Do estudo resulta que o termo educação, muitas vezes, é confundido com a escola, comprometendo a compreensão do que seja sua finalidade. Nota-se que a escola, enquanto instituição normalizadora, não pode ser entendida como única forma de educação devido à própria condição humana de estar em constante aprendizagem-interação com o meio e com os demais.

Palavras-chave: Educação; Desescolarização; Escola.

\section{¿Por qué educación sin escuela?}

\section{Resumen}

Este artículo revisa a los autores y críticos de los procesos de escolarización y polarización de la educación de masas por parte del estado, como Illich, Proudhon, Reimer y Godwin. Presenta una reflexión sobre los posibles efectos sociales de la falta de escolarización de la educación y problematiza el tratamiento dado a la educación y la enseñanza escolar mejorando las posibilidades de pensar la educación más allá de la escolarización. Según el estudio, parece que el término educación a menudo se confunde con la escuela, comprometiendo la comprensión de cuál es su propósito. Se observa que la escuela, como institución normalizadora, no puede entenderse como la única forma de educación debido a que la condición humana misma está en constante interacción de aprendizaje con el medio ambiente y con los demás.

Palabras clave: Educación; No escolarización; Escuela.

\section{Introdução}

O trecho a seguir, extraído de Memórias de um Sargento de Milícias, obra escrita pelo médico e romancista Manuel Antônio de Almeida, retrata a fracassada tentativa do personagem Padrinho em fixar seu afilhado - o protagonista da história - em uma escola do período Imperial.

\footnotetext{
${ }^{1}$ Universidade Federal de Santa Maria/SMED-SM, Santa Maria, tascifeltrin@gmail.com

${ }^{2}$ Universidade Federal de Santa Maria, Santa Maria, fernanda_rigue@hotmail.com

${ }^{3}$ Universidade Federal de Santa Maria, Santa Maria, gcarloscorrea@gmail.com
} 
Entrou este desesperado para a escola, e por princípio nenhum queria estar quieto e calado no seu banco; o mestre chamou-o e pô-lo de joelhos a poucos passos de si; passado pouco tempo voltou-se distraidamente, e surpreendeu-o no momento em que ele erguia a mão para atirar-lhe uma bola de papel. Chamou-o de novo, e deu-lhe uma dúzia de bolos. - Já no primeiro dia, disse, você promete muito... O menino resmungando dirigiu-lhe quanta injúria sabia de cor. Quando o padrinho voltou de novo a buscá-lo achou-o de atenção firme e decidida de não se deixar engodar por outra vez, e de nunca mais voltar, ainda que o rachassem. O pobre homem azuou com o caso (ALMEIDA, 1996, p.28).

O diálogo que se trava entre os personagens é permeado pela presença incômoda de um personagem bem conhecido por todos os leitores: a escola. Para Leonardinho, na altura dos sete anos, a escola de cara já não the pareceu coisa boa, não só pelos castigos físicos, mas o confinamento, a imobilidade e a disciplina iam contra a sua natureza livre, criativa, rebelde e viva. A inserção de Leonardinho no dispositivo escolar é percebida, por ele, como uma drástica inflexão em seu modo de vida, e logo que se percebe "preso", sob o olhar atento do mestre, o menino se utiliza de todo seu vasto conhecimento em peraltices para desvencilhar-se da situação. Entre ele e o professor, em sua figura de autoridade, aclamado pela rigidez e violência, se travou uma disputa digna de ser lembrada, na qual, a esperteza do menino saiu vencedora.

As desventuras do menino se passam em meados do século XIX, entre os anos de $1852 \mathrm{e}$ 1853, mas os elementos que compõem a cena retratada por Manuel Antônio de Almeida, com exceção da palmatória e o castigo no milho, mantêm-se com inacreditável precisão e exatidão na contemporaneidade. $O$ professor, hierarquicamente acima dos alunos, as salas de aula, a disposição das classes, o silêncio dos aprendentes diante da fala do professor, a obediência, a negação dos instintos e das vontades, o sequestro dos corpos, a avaliação, os horários, o disciplinamento e, sobretudo a ideia de que é preciso aprender. Mas você não sabe que é preciso aprender? A criação da necessidade de aprender, articulada à emergência da escola como propagadora de mudanças sociais, dá coesão ao enraizamento e à naturalização de um academicismo excludente em todos os setores que permeiam a vida social.

O aparecimento dessas operações encontra amparo nas propagandas de Estado, cujos canais de expressão trabalham pelo alargamento da oferta de serviços da educação enquanto processo de escolarização, em especial da disseminação de ideias como de uma educação para 
todos, educação para a cidadania, educação para inclusão etc. A percepção do processo de institucionalização das diversas esferas que compõem a vida social, em especial da esfera educativa, movimentou muitos pensadores, filósofos e educadores, entre outros, a pensarem uma educação para além dos muros e paredões institucionais escolares. Segundo Illich (2007, p.101), "Nossa revisão das instituições educacionais leva a uma revisão da imagem que temos do homem. As criaturas de que necessitam as escolas como clientes não têm autonomia nem motivação para se desenvolverem por si mesmas".

Esse movimento do pensar de Illich (2007), nos impulsiona considerar que a escolarização diz de um processo de disciplinarização das mentes e corpos dos indivíduos, por meio das instituições. A finalidade social está fixada na manutenção de garantias ${ }^{4}$ e direitos organizadores da vida social, sob uma perspectiva de organização institucional de Estado. A escolarização é parte de um mecanismo de organização da sociedade cujos dispositivos são detentores de um poder de verdade sobre as possibilidades de desenvolvimento dos indivíduos, a um só tempo orienta e limita quem está inserido no processo e exclui aqueles que não estão. Para Corrêa (2006, p.23), escolarização é o “(...) conjunto de processos educacionais que se dão sob a vigência e respeito a uma lei que regula, indistintamente, todas as instituições de ensino dentro de um território, ou seja, o conjunto de processos educacionais regulados pelo Estado".

Se uma das funções da escola, dentro da perspectiva escolarizante, é impor limites e, também, construir um caminho a um futuro projetado, os teóricos que problematizam esse entendimento de educação, atrelado ao ensino escolar, tiveram o importante papel de alargar esses horizontes de possibilidades. Tendo em vista essas possibilidades, busca-se nesse artigo apresentar perspectivas que problematizam as questões educativas conforme estas têm se apresentado e propagado, estritamente presas à estrutura escolar, em um modelo conservador e propagador de hierarquias, currículos mínimos e normas que mantém determinados estigmas e paradigmas educacionais, os quais atravessam diretamente no modo como crianças e jovens pensam e agem no mundo.

Nesse sentido, o presente artigo visa situar alguns destes pensadores e suas contribuições ao pensamento desescolarizado, com destaque à Educação Libertária, mais especificadamente 
debruçados no pensamento de Ivan Illich (1985; 2007) e Illich et al (1990), Pierre-Joseph Proudhon (2003), Proudhon, Lazaro e Magalhães (2015), Everett Reimer (1983) e William Godwin (1976), cuja postura diante da realidade escolar não se contenta com a mera crítica superficial, mas com uma ampliação das perspectivas sobre a temática, e com a abertura de possibilidades para um novo começo em que o aprender esteja acima do ensinar, pois, “(...) aprender não significa aceitar ideias já concebidas e conhecimentos pré-estabelecidos, mas sim construir o saber sobre a base de autênticos interesses pessoais" (TOMASSI, 1988, p.35, tradução nossa ${ }^{5}$ ). Por meio de uma revisão bibliográfica baseada na literatura especializada, será realizada uma consulta a autores e críticos dos processos de escolarização e polarização da educação das massas pelo Estado.

\section{Os precursores}

Já no século XVIII, alguns intelectuais se destacaram por exercerem forte oposição e problematização ao pensamento social escolarizado, denunciando em seus escritos e discursos os mecanismos arbitrários de dominação das populações, exercido por meio das instituições escolares. François Noël Babeuf ${ }^{6}$, jornalista e defensor de uma educação realizada em ambiente natural, vai de encontro ao pensamento da época que buscava nas Ciências, em especial na área da Medicina, diretrizes que garantissem a máxima efetividade dos processos de escolarização por meio de cuidadosas escolhas arquitetônicas, pela disposição dos materiais, equipamentos e pela higiene. Vindo de uma infância miserável, trabalhando como pedreiro, Babeuf exerceu forte resistência a todas estas medidas relacionadas à escola fortemente burguesa, propondo que a educação fosse oferecida de maneira a tornar possível às crianças se educarem de forma livre e autônoma sem a existência de nenhuma forma de imposição, melhor dizendo, uma educação ativa, prazerosa e gratificante. Nessa perspectiva a educação se associava ao trabalho estabelecendo uma conexão entre inteligência e atividades manuais, aliada aos aspectos políticos inerentes à formação humana. No entanto, considerava importante a participação do

\footnotetext{
${ }^{5}$ Porque aprender no significa aceptar ideas ya hechas y conocimientos preestabelecidos, sino construir el saber sobre la base de auténticos intereses personales.

${ }^{6}$ Sobre Babeuf ver: TOMASSI, T. Breviário del Pensamiento Educativo Libertário. Madrid: Ediciones Madre Tierra, 1988.
}

Periódico Horizontes - USF - Itatiba, SP - Brasil - e019054 
Estado no que chamou de Plano de Educação Nacional para todos, no qual não haveria privilégios, nem excessos. Este Plano, proposto por Babeuf, deveria ser custeado com o lucro da venda dos bens eclesiásticos.

Claude-Henri de Rouvroy - o Conde de Saint-Simon - filósofo e economista teve uma vida muito distinta da levada por Babeuf, mas de maneira semelhante negou a institucionalização escolar e seu disciplinamento. Saint-Simon (1816) centrou seus esforços em distinguir os conceitos de instrução e educação sendo que, por educação, o autor compreende os modos de vida dos indivíduos, preocupando-se com a solidariedade e com os sentimentos morais. SaintSimon (1816) percebeu a figura do professor como prejudicial ao pleno desenvolvimento dos estudantes, assim, propôs uma educação sem professores, pela estratégia do ensino mútuo.

Jean-Joseph Jacotot (2008), na mesma linha, afirmou que o professor não é indispensável nem precisa conhecer o que ensina. Sua tarefa é colocar os alunos em condições mínimas de buscar. Para ele, o autodidatismo é à base de qualquer forma de aprendizagem. Jacotot (2008) defendeu três princípios fundamentais para a compreensão da educação humana: 1ํ) os homens possuem inteligências iguais e as diferenças dependem da influência recebida; 2 ํ) tudo está em tudo- basta qualquer elemento de qualquer disciplina para que a inteligência possa descobrir todos os elementos constitutivos e colocá-los em relação com tudo o mais que conhecem; 3ํ) qualquer um tem a possibilidade de se auto instruir.

No século XIX, Friedrich Nietzsche, filósofo e educador, publicou as obras Aurora, em 1881, e A Gaia Ciência, em 1882. Ambas defendem a ideia de uma autoeducação e condenam a necessidade de castigos através dos quais a escola transformava homens em meros cordeiros. "Para a nova educação do gênero humano. - prestai auxílio, vós que sois prestativos e bem intencionados, a esta última obra - afastar do mundo o conceito de castigo, que se alastrou sufocando o mundo inteiro!" (NIETZSCHE, 2004, p.161).

Além destes pensadores acima citados, poder-se-ia citar muitos outros que desenvolveram uma percepção problematizadora e sensível às subjetivações inerentes à institucionalização e singularização, em relação ao que se concebia por educação em cada período, tais como: Piotr Kropotkin (1910; 1913), Lev Tolstoi (1862; 1888), Mikhail Bakunin (1968), Pietro Gori (1948), Luigi Fabbri (1912), Max Stirner (2009) etc.

Desde então, um breve olhar sob a temática nos leva a uma quantidade imensa de 
pessoas que fizeram uma análise da situação e propuseram estratégias para se produzir diferentes e múltiplas composições de se pensar educação e suas garantias. Tomam parte entre as propostas para a educação questões como a problematização do disciplinamento corporal ${ }^{7}$, a alfabetização como possibilidade para a pesquisa ${ }^{8}$, a necessidade de uma educação integral, como propulsora da revolução sociocultural ${ }^{9}$, a valorização da experiência nos processos educativos $^{10}$, o respeito ao desenvolvimento, liberdade e autonomia da criança ${ }^{11}$, o fim da autoridade sobre o indivíduo ${ }^{12}$.

Nesse sentido, reconhecendo a existência de todas essas propostas, realizaremos em seguida um breve apanhado acerca da Educação Libertária, por meio de seus renomados pensadores, com intuito de apresentar suas perspectivas e horizontes de possibilidade.

\section{A Educação Libertária e Seus Pensadores}

Os horizontes e as possibilidades no campo da educação, por muito tempo, permaneceram engessados e intactos em meio a tendências e perspectivas que se preocupavam apenas em aperfeiçoar os caminhos e verticalizações da escolarização, especialmente da relação de ensino-aprendizagem. Em meio a burocratizações, disciplinas, métodos e pedagogias vigentes, múltiplas relações de forças operaram como estratégia para a universalização da escola enquanto ambiente único e formal de construção de conhecimentos, deixando de lado as outras possibilidades em educação na sua totalidade.

Preocupados em entender e ir além do que este dispositivo do Estado, que prima por uma 'educação para todos', busca-se nesse momento ir ao encontro do pensamento de indivíduos que problematizaram a escolarização, bem como suas normatizações, no contexto da

\footnotetext{
7 Ver: BELTRÃO, lerecê Rego. Corpos dóceis, mentes vazias, corações frios. didática: o discurso científico do disciplinamento. São Paulo: Editora Imaginário, 2000.

${ }^{8}$ Ver: BAZIN, M. O cientista como alfabetizador técnico. In: ANDERSON, S.; BAZIN, M. Ciência e (in)dependência. Lisboa: Livros Horizonte, 1977. p.94-98. v. 2.

${ }^{9}$ Ver: ROBIN, Paul. Manifiesto a los partidários de la educacion integral. Barcelona: Pequena Biblioteca Clamvs Scriptorivs, 1981.

${ }^{10}$ Ver FAURE, Sebastien. La ruche: uma experiência pedagógica. Madri: La Malatesta, 2013.

${ }^{11}$ Ver FERRER y GUARDIA, Francisco. La escuela moderna. Madrid: La Malatesta, 2013.

12 Ver STIRNER, Max. O falso princípio de nossa educação. São Paulo: Editora Imaginário, 2001.
}

Periódico Horizontes - USF - Itatiba, SP - Brasil - e019054 
Educação Libertária. Autores como: Elisée Reclus (1985), Pierre-Joseph Proudhon (1865; 2003; 2015), Everett Reimer (1983), William Godwin (1976) e Iván Illich (1985; 1990; 2007), que permaneceram à mercê de breves considerações em obras tidas como referência no campo da historiografia da educação serão apresentados, de modo a problematizar os contextos, caminhos e descaminhos que a educação tomou em meio à escolarização. Dentre esses estão envolvidos uma série de pensadores anarquistas. Sobre o anarquismo,

O anarquismo surgiu de um protesto moral contra a opressão e a injustiça. As primeiras sociedades humanas presenciaram uma luta constante entre aqueles que queriam mandar e aqueles que se negavam a obedecer ou mesmo mandar. O primeiro anarquista foi a primeira pessoa que sentiu a opressão de outra e rebelou-se contra ela. (...) Por ser uma tendência reconhecível na história humana, a linha do tempo do anarquismo, em tempos de pensamento e fatos, deve buscar um passo de milhares de anos atrás (MARSHALL, 2010, p.3-4).

Ao mesmo tempo, segundo o que argumenta Woodcock (2002, p.07),

Do ponto de vista histórico, o anarquismo é a doutrina que propõe uma crítica à sociedade vigente; uma visão da sociedade ideal do futuro e os meios de passar de uma para outra. A simples revolta irracional não faz de ninguém um anarquista, nem a rejeição do poder terreno com bases filosóficas ou religiosas (...). Sob o aspecto histórico, o anarquismo preocupa-se, basicamente, com o homem e sua relação com a sociedade.

Assim, a fluidez do anarquismo no campo da educação conduz a transformações e movimentos que remetem a permanentes incertezas, porém, possibilidades que projetam atitudes libertárias, indo ao encontro da “(...) permanente flutuação” (WOODCOCK, 2002, p.17). Nesse sentido:

Descrever a teoria essencial do anarquismo é um pouco como tentar lutar com Proteu, pois as próprias características da atitude libertária - a rejeição ao dogma, a deliberada fuga a sistemas teóricos rígidos e, acima de tudo, a ênfase que dá à total liberdade de escolha, à primazia do julgamento individual - criam imediatamente a possibilidade de uma imensa variedade de pontos de vista, inconcebíveis num sistema rigorosamente dogmático (WOODCOCK, 2002, p.17).

Os preceitos anarquistas não encerraram, e estão em vigência desde 1840 no território Periódico Horizontes - USF - Itatiba, SP - Brasil - e019054 
Europeu, mesmo após muitas tentativas de estagnação por parte de outros movimentos verticalizados. Para Kropotkin (1910), um importante representante do movimento anarquista, a anarquia é um:

(...) nome dado ao princípio ou teoria de vida e conduta em que a sociedade é concebida sem governo. A harmonia em tal sociedade é obtida, não pela submissão a leis, ou pela obediência a alguma autoridade, mas pela livre concordância estabelecida entre vários grupos, territoriais e profissionais, livremente constituídos em favor da produção e do consumo, e também para a satisfação da infinita variedade de necessidades e aspirações de um ser civilizado (KROPOTKIN, 1910, p.1).

Um dos principais pontos de divergência entre os termos educação e escolarização, para os propagadores da Educação Libertária, está situado no campo da liberdade. Aprende-se por vontade, mas à escola se vai por obrigação; logo, se observarmos a estrutura escolar, vê-se aí um complexo modo de investir em um determinado tipo e forma de educação. A disciplina, os horários e tempos para cada atividade, os currículos mínimos pensados para uma formação específica, não tem como preocupação a vontade dos estudantes, o que nos permite considerar que se tratam de uma multiplicidade de elementos que os conduzem à perda da autonomia. pensamento também é desestimulado, como a criatividade e a vontade de aprender. Só se aprende o que o professor pode ensinar, e os órgãos responsáveis e reguladores autorizam. Assim os processos educacionais são reduzidos à leitura/escrita, pergunta/resposta, verdadeiro/incorreto, em uma espécie de jogo mecânico e automático, naturalizado, que perde seu sentido se tirado do contexto da sistematização burocrática que adquiriu o ambiente escolarizado.

De outro lado, a educação como um todo compreende a ampla movimentação do pensamento e do corpo em busca de algo que deseja, que lhe seja intrigante e que, ao menos, Ihe chame a atenção. A educação, entendida como processo educativo, é singular, particular para cada indivíduo. Em contrapartida, a escola segue uma ação e lógica padronizadora, com um discurso individualizante que opera no cerne de uma totalização. Nesse sentido, os pensadores da Educação Libertária propuseram não o fim da escola, mas a eliminação de princípios que impedem o desenvolvimento da aprendizagem, como o autoritarismo, a hierarquia escolar, o disciplinamento, a subordinação ao Estado, à Igreja e às instituições. Problematizar as verdades 
naturalizadas nos discursos proliferados já escolarizados e, assim apresentar novas compreensões ao que chamamos e entendemos como processo educativo.

Tina Tomassi (1988), historiadora e interessada nas concepções educativas do pensamento libertário, compreende que a educação precisa potencializar os impulsos naturais para a liberdade interior e exterior, para a iniciativa e a responsabilidade. Conforme a autora, educadores e pais não devem se apoiar em ordens e conselhos de qualquer tipo:

Todos concordam em considerar que as massas as quais a ignorância tem impedido há tempos de tomar consciência dos seus próprios direitos e de sua própria força devem participar sem qualquer limitação na cultura, até agora privilégio das classes dominantes avidamente acumulado e apenas na medida em que tem sido útil para estas; todos rejeitam os moldes tradicionais da escola, por terem sido estruturados não para despertar, mas para alienar as consciências, para impor secretamente as ideias desejadas por quem comanda, para apagar em conformismo a sede de liberdade e o desejo de iniciativa. (TOMASSI, 1988, p.10, tradução nossa ${ }^{13}$ ).

Com essa mesma compreensão, os pensadores Elisée Reclus (1985), Francisco Ferrer y Guárdia (2013), Pierre-Joseph Proudhon (1865; 2003; 2015), Iván Illich (1985; 1990; 2007), Everett Reimer (1983) e William Godwin (1976) propuseram problematizar a escolarização, fortemente impulsionados por seus anseios de teor anarquista. Não se pretendia desse modo, a inexistência de escolas e espaços formais para o desenvolvimento e a construção de conhecimentos, mas, sim, novas possibilidades para a construção de saberes, para além das verticalizações capturantes (horários, conteúdos, disciplinas, distinções de cargos, burocracias etc.) disseminadas e perpetuadas pelos bancos escolares. Nesse sentido, nessa oportunidade, trataremos que apresentar brevemente quem foram esses pensadores com o propósito de compreender suas concepções acerca da educação.

Elisée Reclus, oriundo de uma família humilde, teve uma trajetória empenhada no estudo e conhecimento da área da Geografia, por sua vez, destacou-se também em discussões sociais e

\footnotetext{
13 Todos están de acuerdo em considerar que las masas a las que la ignorancia ha impedido hasta ahora tomar conciencia de sus propios derechos y de su propia fuerza deben participar sin ninguna cortapisa en la cultura, hasta ahora privilegio de las clases dirigentes que la han acaparado avariciosamente y sólo en la medida que les ha sido útil; todos rechazan los moldes escolares tradicionales, por haber sido estructurados no para despertar sino para alienar a las conciencias, para imponer solapadamente las ideas deseadas por el que manda, para apagar en el conformismo la sed de libertad y el deseo de iniciativa.
}

Periódico Horizontes - USF - Itatiba, SP - Brasil - e019054 
políticas, exercendo fortemente a militância. Em meados do século XIX, na França, esteve envolvido com movimentos políticos e permaneceu ativo com seus preceitos anarquistas. Esteve a par da I Internacional, juntamente com Bakunin. Seu caráter libertário esteve sempre atrelado aos saberes do campo da Geografia, de modo a inserir reflexões e problematizações mais complexas no campo político e social. Segundo Reclus (1985, p.70):

(...) do ponto de vista especialmente geográfico, é importante saber como as formas políticas das sociedades correspondem normalmente às diversas formas terrestres na evolução da humanidade; pode-se estabelecer a este respeito regras gerais, que prevaleceram enquanto a constituição de grandes Estados centralizadores - que dispunham de formidáveis meios de coerção - não suprimisse os contrastes originários.

Ao mesmo tempo, Francisco Ferrer y Guárdia veio ao mundo em 1859 na cidade de Alella. $\mathrm{Na}$ infância estudou em escolas jesuítas e, quando jovem concebeu-se adepto do pensamento de cunho liberal. Segundo Gonçalves (2009, p.42):

Ferrer foi um estudioso das transformações científicas e sociais que ocorriam em Barcelona, a proximidade desta cidade com a França, que já havia declarado a República - a "Revolução Gloriosa" de 1868, a qual destituiu a monarca absolutista Isabel II de Bourbon - e estabeleceu um outro governo e uma nova constituição; tudo isto e mais outros fatores políticos que Ferrer vivenciou em seus 20 anos, fizeram que ele tomasse a decisão de direcionar seu pensamento ao Republicanismo.

Por sua vez, após estratégias e jogos de poder que foram se organizando e novos rumos que o movimento republicano foi tomando e com os rumos do Republicanismo, Ferrer ao contatar várias instâncias de intelectuais e ativistas, começou a direcionar seu pensamento ao Republicanismo de base social, com pendor libertário (GUSSINYER, 2003).

Após ter se afastado das ideias republicanas, “(...) sua bandeira de luta tornou-se então a Educação. Escreveu um livro de gramática em Espanhol e começou a colocar em prática seu pensamento educacional" (GONÇALVES, 2009, p.45). Em agosto de 1901, fundou La Escuela Moderna de Barcelona e “(...) recebeu o apoio de livres-pensadores, franco-maçons, republicanos radicais e anarco-sindicalistas" (p.46). Sobre a Escola Moderna fundada por Ferrer, Gonçalves (2007) coloca que: 
A primeira aula aconteceu no dia 8 de setembro de 1901 (...) Por não ser a escola financiada pela Igreja ou pelo Estado, ela era financiada pelas famílias dos seus alunos que pagavam conforme sua renda, num sistema chamado de gradação de cotas. Com um pequeno grupo de professores, Ferrer iniciou sua obra educativa. $\mathrm{O}$ primeiro passo foi fundar a editora que lhe daria suporte nos livros a serem utilizados em sua escola a fim de realizar seu intento de conduzir uma escola racionalista, visto que Ferrer não considerava que os livros existentes iriam servir ao processo educativo desenvolvido por ele (...) O espaço escolar era preparado para responder aos aspectos metodológicos apregoados por Ferrer. Havia uma preocupação com o aspecto higiênico por isso as salas de aula eram arejadas e bem iluminadas (GONÇALVES, 2007, p.47).

Ao mesmo tempo, eram realizadas atividades externas ao espaço escolar, envolvendo reconhecimento de espaços comerciais, artísticos e culturais dos seus arredores. Debates e reflexões faziam parte de uma prática pedagógica para além da seriação escolar, valorizando saberes e conhecimentos individuais que se multiplicavam no compartilhamento por meio da coletividade. Para Gonçalves (2007),

\begin{abstract}
Apesar de Ferrer não se dizer um anarquista e não ligar a sua escola a este movimento; sua ligação com os anarquistas era evidente, sendo que sua editora traduz obras de pensadores libertários europeus a fim de formar militantes operários e sindicalistas, e, em 1903 Ferrer patrocinou e dirigiu um jornal "La Huelga General" (A Greve Geral), em que publicou obras de anarquistas e defendeu a greve como instrumento de luta das classes operárias (GONÇALVES, 2007, p. 49).
\end{abstract}

No dia 13 de outubro de 1909, após um longo período de perseguição, Ferrer foi fuzilado e acabou morrendo, deixando um legado de Educação Libertária, em meio ao contexto adverso em que vivia na época.

Ao mesmo tempo, podemos destacar nessa oportunidade o pensamento desenvolvido por Pierre-Joseph Proudhon, um dos pioneiros na problematização da educação escolar oferecida pelo Estado e/ou pela Igreja às classes populares, entre os anos de 1809-1865. Nascido na França, nos anos 10 do século XIX, em uma família de camponeses muito pobres, iniciou no ofício de pastor de ovelhas aos nove anos de idade, devido a sua precocidade no mundo do trabalho. Acabou por abandonar a escola e toda a sua formação intelectual foi desenvolvida enquanto autodidata.

Periódico Horizontes - USF - Itatiba, SP - Brasil - e019054 
Formação esta que ganhou um impulso em sua adolescência quando passou a trabalhar como tipógrafo. Proudhon aproveitou seu contato com diversos materiais impressos em seu local de trabalho para se instruir intelectualmente. Sua obstinação pela leitura e pelo conhecimento garantiu uma bolsa de estudos em Paris, onde frequentava diversos cursos na Sorbonne, Collège de France, Conservatoire des Arts et Métiers e, assim, se utilizava do acervo da Biblioteca Mazarine com uma frequência espetacular. A vida de estudante, contudo, não desvanece as lembranças da infância miserável sem condições de comprar os livros escolares, contudo, é a visão de seus pais perdendo seu último pedaço de terra e obrigados a viveram em uma minúscula casa no subúrbio, que acabou influenciando diretamente sua luta pelo fim da propriedade privada.

A experiência de vida de Proudhon no seio do povo, aliada a seu contato privilegiado com obras inacessíveis à sua classe social, foram os pilares que permitiram ao pensador e escritor projetar em suas obras, de maneira única, a visão das classes populares da estrutura social, com destaque para a organização educacional e escolar. Considerado, por alguns, o pai do movimento anarquista, publicou obras críticas ao sistema capitalista e opressor das massas como: A Filosofia da Miséria (1846); O que é a Propriedade? Ideia Geral da Revolução no Século XIX (1840); Da Justiça na Revolução e na Igreja (1858); Princípio Federativo (1863); Da Capacidade Política das Classes Trabalhadoras (1865). Segundo o que argumentou acerca da anarquia, Proudhon (2015) afirma que "a anarquia seria a forma de governo ou constituição, na qual a consciência pública ou privada, formada pelo desenvolvimento da ciência e do direito, é por si só suficiente para a manutenção da ordem e para a garantia de todas as liberdades" (PROUDHON, 2015, p.93).

Da obra intitulada Da Capacidade Política das Classes Trabalhadoras (1865), podemos destacar o capítulo denominado - Instrução Pública: condições de um ensino democrático através do qual o autor expõe que a instrução do povo, tal como ele tem direito de obtê-la, é incompatível com o sistema econômico-político adotado pela Oposição e pelo Governo. No capítulo seguinte chamado - Condições de um ensino democrático - Proudhon se distancia do pensamento, que anos mais tarde virá a se tornar o Socialismo Marxista, o qual insiste em uma aparelhagem de Estado que organize de forma centralizada a Instrução pública sem modificar a estrutura escolar. Para ele, a manutenção do mecanismo escolar beneficiaria apenas a classe que a governa ideologicamente. Michel Foucault (1979), em Sobre a Justiça Popular, vai vir a 
questionar, anos mais tarde, as implicações da manutenção de estruturas historicamente empregadas para coagir o povo. Para ambos, a estrutura escolar está infestada pelas ideologias da classe dominante de maneira que apenas inverter as figuras em posição de comando não traria o resultado desejado, sendo necessário que novos instrumentos fossem criados. Logo,

Não bastava, portanto, destruir a instituição estatal ou a educação cristã. Era preciso compreender que enfrentar o problema da educação oferecida às classes laboriosas era antes de tudo levantar uma questão muito mais profunda: era denunciar o caráter classista e opressor que existia na educação fornecida ao povo (PROUDHON; LAZARO; GUIMARÃES; 2015, p.15).

Assim, a questão da educação para Proudhon não poderia ser resolvida sem uma profunda renovação do que se concebia por instrução, o que só seria possível por uma revolução de toda a sociedade. "No momento em que a verdadeira educação fosse uma realidade, neste momento já estaria acontecendo a revolução, porque a educação capaz de formar o homem da revolução é parte dela mesma" (PROUDHON; LAZARO; GUIMARÃES; 2015, p.15).

Proudhon destaca a necessidade de se retirar a educação do povo das mãos do Estado, pois este recolhe inúmeras vezes mais do que investe ou retorna o valor dos impostos em educação, de maneira a condenar as classes subalternas a uma educação deficitária, desconectada da vida, do contexto e da experiência, que não prepara nem estimula o conhecimento, mas torna os homens escravos de um comando por não possuir esclarecimento suficiente para agirem e pensarem enquanto seres autônomos.

Se a educação fosse antes de mais nada experimental e prática, reservando os discursos apenas para explicar, resumir e coordenar o trabalho, se fosse permitido aprender pelos olhos e pelas mãos aquilo que não pode aprender pela imaginação e pela memória, logo veríamos com as formas do trabalho, multiplicarem-se as capacidades; todos, concebendo a teoria de alguma coisa, saberiam por isso mesmo a língua filosófica e poderia acontecer, ao menos uma vez na vida, que alguém pudesse criar, modificar, aperfeiçoar, dar provas de inteligência e de compreensão, produzir sua obra-prima, ou seja, em uma palavra, mostrar-se homem (PROUDHON, 2003, p.221).

Além disso, para ele a educação escolar vai por caminhos que não levam ao florescer do conhecimento, mas à dominação; nesse ínterim, chama a atenção que “(...) a escola de minas, 
não serve para formar mineiros, do mesmo modo que a escola de artes e ofícios" (PROUDHON, 2003, p.179), não forma artesãos, mas sim chefes e diretores, ou seja, a função dessa instituição escolar é instrumentar uma aristocracia com poder suficiente para comandar. Na escola anarquista, por outro lado, “(...) a função do saber ler e escrever está além de simplesmente escrever nomes, palavras, frases ou textos. Ao contrário, saber ler e escrever significa a condição para o conhecer, para o raciocinar, para o reivindicar e para o lutar" (PROUDHON; LAZARO; GUIMARÃES, 2015, p.57).

Dessa forma Proudhon propõe que cada comuna decida como organizar suas escolas e nestas os estudantes aprendam tudo o que quiserem livremente, e em contraponto aprenderão uma atividade prática cujo trabalho pagará seus estudos e também os gastos com a manutenção de professores e os materiais de que precisarem. Eximindo os pais de gastos, e impedindo a mediação do Estado que consome maior parte do dinheiro arrecadado sem se importar com as péssimas condições de ensino relegadas ao povo. Segundo Proudhon (2015), “O povo é um ser coletivo. (...) extraímos da coletividade do ser popular a prova de que ele é perfeita e superiormente capaz, de que ele pode tudo, e não necessita de ninguém. Trata-se apenas de colocar em ação suas faculdades" (PROUDHON, 2015, p.77).

Do mesmo modo, um dos tantos pensadores preocupados em problematizar a escola foi Everett Reimer. Sua trajetória entre os anos de 1910 e 1998 esteve atrelada à defesa da desescolarização, juntamente com seu amigo Iván Illich. Reimer não se considerava um anarquista, embora suas ações e perspectivas políticas e sociais tivessem caráter libertário. Dentre suas publicações, a de maior repercussão foi "A escola está morta: alternativas em educação", publicada pela livraria Francisco Alves Editora S.A., traduzida por Tonie Thompson no ano de 1983. Segundo ele, “(...) a escola é a maior empresa do mundo: maior mesmo do que a agricultura, a indústria ou a previdência social" (REIMER, 1983, p.20). O investimento que é feito para sustentar a grande máquina da escolarização é, para o autor, sem sombra de dúvidas, muito significativo quando comparado ao rádio e à televisão. Segundo Reimer $(1983,21)$ :

A educação escolar é uma forma quase perfeita de imposto regressivo, pago pelos pobres para beneficiar os ricos. Escolas são sustentadas, principalmente, por tributos gerais que, no final, recaem mais sobre as classes menos favorecidas do que sua incidência direta poderia sugerir. 
A escolarização que, teoricamente, possui uma capacidade exorbitante de transformação social, significa para o autor uma restrição gigantesca no desenvolvimento humano de crianças, adolescentes, comunidades e famílias. No que se refere à família e relações parentais, Reimer (1983) afirma que,

Ir à escola significa abandonar a vida tradicional, mudar-se para lugares diferentes, deixando de lado tarefas concretas, para dedicar-se a atividades da mente e da linguagem, trocando os costumes, indumentária e alimentação tradicionais pelos da cidade distante ou grande. Os pais, freqüentemente, preferem conservar seus filhos na comunidade tradicional suportando a carga a que estão acostumados, restringidos aos prazeres que os meios primitivos possam oferecer. Reconhecem, no entanto, que isto implica aceitar a contínua dominação pelos outros, a contínua dependência nas crises de fome, guerra e doenças, o distanciamento cada vez maior dos que gozam fortuna, poder e respeito. Quando a escolha se torna inevitável, a maioria dos pais analfabetos optam pela educação escolar de seus filhos (REIMER, 1983, p.24, sic).

Quanto à dependência dos indivíduos de baixa renda aos ambientes escolares, Reimer (1983) argumenta que isso se deve à situação de vulnerabilidade provocada pela disparidade social e econômica significativa existente no capitalismo. Os sistemas educacionais de seleção, castração, avaliação e meritocracia que entornam as estratégias de formação da escola, percebe o aluno enquanto número, registro, simplesmente um dado. Embora existam ditas tentativas de aperfeiçoamento por parte de professores e responsáveis quanto aos modos e estratégias de captar o aprendizado para os alunos, o fato é que o fim é sempre homogêneo, aluno versus registro. Esse tipo de tratamento é aceito e equivalente a como as pessoas são tratadas em demais setores de segregação ocupados por esses indivíduos na sociedade, na indústria etc.

Reimer é problematizador ao questionar a tutela que a escola tem sob a vida das pessoas, além de sinalizar a constante separação entre escola e realidade, “(...) a separação cada vez maior entre a escola e o cotidiano alarga o abismo existente que esforço algum pode transpor" (REIMER, 1983, p.37). Além do pensamento complexo e rizomático de Reimer, podemos destacar as ideias e perspectivas de Iván Illich.

Reconhecido por seus estudos sobre a instrução, Iván Illich propõe que se pense a educação como um problema e não como uma solução engendrada, para propagar seu entendimento da situação da escola e do conhecimento na atualidade, publica obras como: 
Desescolarizar a Sociedade (2007), Na Ilha do Alfabeto (1990), A Vaca Sagrada (1968), La Alternativa a la escolarización (1974). Sobre essa educação desescolarizada, escreveu Ivan Illich (2007, p. 75):

\begin{abstract}
Um bom sistema educacional deve ter três propósitos: dar a todos que queiram aprender acesso aos recursos disponíveis, em qualquer época de sua vida; capacitar todos os que queiram partilhar o que sabem a encontrar os que queiram aprender algo deles e, finalmente, dar oportunidade a todos os que queiram tornar público um assunto a que tenham possibilidade de que seu desafio seja conhecido (...) é preciso usar a tecnologia moderna para tornar a liberdade de expressão, de reunião e imprensa verdadeiramente universal e, portanto, plenamente educativa. As escolas estão baseadas na suposição de que há um segredo para tudo nessa vida; de que a qualidade da vida depende do conhecimento desse segredo; de que os segredos só podem ser conhecidos em passos sucessivos ordenados; de que apenas professores sabem revelar corretamente esses segredos. Um indivíduo de mentalidade escolarizada concebe o mundo como uma pirâmide, composta de pacotes classificados; a eles só têm acesso os que possuem os rótulos adequados. Seu objetivo deve ser facilitar o acesso ao aprendiz: se não puder entrar pela porta, permitir-lhe que entre pela janela, olhe para dentro da sala de controle ou do parlamento. Ainda mais, essas novas instituições devem ser canais aos quais o aprendiz tenha acesso sem credenciais ou linhagem- logradouros públicos em que colegas e pessoas mais idosas, fora de um horizonte imediato, tornem-se disponíveis.
\end{abstract}

Em A Ilha do alfabeto (1990), o autor estabelece uma diferenciação entre a alfabetização especializada, segundo ele “(...) aquisição da capacidade de ler e escrever" (p.14), e a alfabetização laica, a qual corresponde a uma forma “(...) peculiar de percepção, na qual o livro se torna o símbolo fundamental de uma nova forma de conceber a si mesmo e sua própria colocação" (ILLICH, 1990, p, 12). Segundo o autor,

A verdadeira alternativa à escolarização não devia consistir em um tipo diferente de instituição educativa, ou em um projeto que inserisse a instrução em todos os aspectos da existência, mas em uma sociedade que promovesse uma atitude diferente das pessoas em relação aos instrumentos. A partir daí, minha curiosidade e minhas reflexões se focalizaram nas circunstâncias históricas que determinaram a insurgência do próprio conceito de necessidade da instrução (ILLICH, 1990, p, 16).

A partir de seu aprofundamento sobre a criação de necessidades relativas ao processo de leitura associada à escrita e ao avanço hegemônico do tipo de educação escolar, Illich passou a 
observar e interessar-se pelas estruturas mentais e formas de pensar que surgiram desses processos, conforme afirma em uma de suas obras: "Comecei a discernir os sinais que a necessidade de instrução deixa na estrutura mental de seus participantes" (ILLICH, 1990, p.14). Ao mesmo tempo,

Em toda a parte se admite que os alunos recebam uma assim chamada instrução, da qual se admite que a escola tenha o monopólio, e que esta instrução seja necessária para transformar os alunos em bons cidadãos, cada um dos quais deverá estar ciente do nível escolar atingido em sua "preparação para a vida". Eis, portanto, como a liturgia escolar cria a realidade social na qual a instrução é considerada um bem necessário (ILLICH, 1990, p.17).

Illich (1985) critica a escolarização afirmando que, “(...) na escola, alunos matriculados se submetem a professores diplomados para obter também eles diplomas; ambos são frustrados e ambos responsabilizam a insuficiência de recursos - dinheiro, tempo e instalações" (ILLICH, 1985, p.123). Do mesmo modo, se permite relacionar a dependência dos espaços escolares aos meios políticos da sociedade,

\begin{abstract}
Assim, se conseguirmos mudar o estilo da liderança política, promover os interesses de uma ou outra classe, transferir a propriedade dos meios de produção do domínio privado para o domínio público, supomos que também mude o sistema escolar. As instituições educacionais que desejo propor estão concebidas para servir uma sociedade que ainda não existe, se bem que a frustração atual no tocante às escolas seja grande força potencial para impulsionar a mudança que permita novos arranjos sociais (ILLICH, 1985, p.125).
\end{abstract}

Com base nas críticas e problematizações de Illich (1985), permite-se considerar que para ele, educar para além de escolarizar, possibilitará construir indivíduos pensantes, autônomos e ativos no contexto social, além de afirmar que na escolarização, quando alunos e professores estabelecem relação estritamente disciplinares, não é possível alcançar a amplitude da complexidade da educação, em todas as suas dimensões. Para Illich (1985, p.163):

O relacionamento de mestre e aluno não está restrito à disciplina intelectual. Tem sua contrapartida nas artes, na física, religião, psicanálise e pedagogia. Cabe também no alpinismo, ourivesaria, política, carpintaria e administração de pessoal. O que é comum a todo verdadeiro relacionamento mestre-aluno é a 
certeza de ambos que seu relacionamento é literalmente incalculável e, de maneiras bem diversas, um privilégio para ambos.

A noção de sociedade convivencial, proposta por lllich, vem ao encontro da criação de um dispositivo para contrapor o capitalismo exacerbado que interfere diretamente na escolarização, indo ao encontro da produção de ferramentas que acarretem a liberdade individual em meio a comunidades.

William Godwin (1976) foi um jornalista inglês, filósofo político e novelista. Ele é considerado um dos primeiros expoentes do utilitarismo, e um dos primeiros proponentes modernos do anarquismo. Tem em sua obra, O Inquisidor: Reflexões sobre Educação, Costumes e Literatura, um produto de cunho nitidamente educacional. Percebe-se em sua escrita que o autor potencializa o leitor a cultivar a mente através do aprendizado, para que, assim, lhe seja possível alcançar a virtude e a sabedoria.

Godwin (1976) considera a liberdade a mais desejável de todas as vantagens. Pensa que o conhecimento passado seja de bom grado e respeitado a ponto de não infringir ou barrar um pensamento de obter escolhas. Pode-se até pensar que sua única vontade de imposição seja aquela que deseja despertar em determinados indivíduos a vontade de adquirir conhecimentos.

O ser humano é capturado o tempo todo por uma máquina de ser governado. O Estado deixa marcas que muitas vezes não sentimos. Ou seja, como nascemos dentro de um dispositivo educacional de imposições, a falta de opção nos coloca dentro de um fluxo e nos transforma em marionetes. No entanto, quando nos são dadas alternativas, essas caem quase sempre em uma educação obrigatória, ou, como nos diz Corrêa (2006), ao diferenciar o que é educação, caímos no poder da escolarização.

Uma das características inerentes à mente humana é a sua capacidade de crescer. $\mathrm{E}$ no momento em que o indivíduo resolve manter-se fiel a determinados princípios, (...) ele está renunciando a uma das mais belas qualidades do homem. Pois o instante em que deixa de indagar, é o instante em que morre intelectualmente (GODWIN, 1976, p.615).

Godwin (1976) menciona esse aspecto que impossibilita a mente de crescer. Acreditamos que esse é um dos maiores sequestros que o Estado nos tira. Ou seja, a partir da imposição por modelos de escolarização conteudistas somos forçados sem perceber a querer sempre mais Periódico Horizontes - USF - Itatiba, SP - Brasil - e019054 
educação quando na verdade estamos pedindo mais governança. Desejamos as "estrelinhas" do bom comportamento.

O projeto de uma educação nacional deveria ser uniformemente desencorajado devido à sua óbvia aliança com o governo nacional. Esta é uma aliança de natureza ainda mais formidável do que a velha e muito contestada aliança da igreja com o estado. Antes de colocarmos uma tão poderosa máquina sob a direção de um agente tão ambíguo, nos convém considerar bem o que estamos fazendo. O governo não falhará em usá-la, para fortalecer suas mãos, e perpetuar suas instituições (GODWIN, 1976, p.616).

A partir de uma liberdade pela vontade, Godwin (1976) mostra uma possibilidade de educação que inclui o desejo como um dos bens mais preciosos. Neste sentido, é o desejo que nos impulsiona e não um modelo estatal que nos direciona.

\section{Considerações}

Este artigo buscou apresentar uma reflexão sobre os possíveis efeitos sociais de uma desescolarização da educação. Além disso, problematizar o tratamento dado à educação e ao ensino na escola, a partir de pesquisas e estudos dedicados a esse tema. Tratou-se de uma revisão bibliográfica baseada na literatura especializada por meio de consulta a autores e críticos dos processos de escolarização e polarização da educação das massas pelo Estado. A partir das revisões, buscou-se demonstrar que o termo educação, muitas vezes, é confundido com a escola, o que compromete a compreensão do que seja a finalidade da educação, e acarreta inúmeros problemas de ordem epistemológica e social.

Nota-se que a escola, enquanto instituição normalizadora, não pode ser entendida como única forma de educação devido à própria condição humana de estar em constante aprendizagem-interação com o meio e suas relações e com os demais. Limitar os processos educacionais aos processos instigados e realizados dentro do espaço escolar, em período prédeterminado, torna a própria concepção de aprendizagem paradoxal.

Verificou-se que é preciso abster-se da imagem idealizada da escola, de uma imagem uniformizadora e aceitar compreendê-la na sua diferença. Para isso, faz-se necessário que os 'profissionais' que atuam na escola questionem a realidade e busquem conhecê-la em sua 
multiplicidade, a fim de compreenderem sobre quais são (por vezes) as raízes da violência. A tentativa de impor regras a fim de se alcançar a "escola dos sonhos" é, além de falha, provavelmente o motor para a revolta e a violência, a tristeza e o adoecimento.

Por meio das perspectivas apresentadas pelos pensadores que problematizam a escolarização, sendo eles anarquistas ou não, o que se concebe nesse estudo é um cenário de questionamento ao jogo de forças em que a escolarização age sobre a vida e os corpos dos indivíduos. Para educar é preciso causar no indivíduo um ato voluntário e, para tanto, defendese ser preciso que o mesmo compreenda tais motivos.

Em outras palavras, aqui se pensam duas formas nas quais o conhecimento pode estar envolvido: educação desescolarizada e educação vinculada às instituições. O primeiro, nomeado de educação desescolarizada, tanto pode aconselhar um tipo de noção, evidenciando os benefícios que fundamentalmente estarão ligados à obtenção deste conhecimento ou serão consequência dele. $E$, um segundo, compreendido como uma educação ligada às instituições escolares que pode impor o conhecimento de forma arbitrária, por meio de persuasão ou de intimidações, explanando que a aquisição do conhecimento contará com uma avaliação, condicionando (ou não) a aprovação e que, a recusa de adquiri-lo, provocará a contrariedade. Neste segundo, acreditamos ser um modo de escolarização, tão presente em nosso contemporâneo e que diz das estratégias empregadas pelo Estado e a seus mecanismos de controle. Escolarização tomada por limites, que afeta corpos (de geração a geração) independentemente de quais sejam os esforços individuais empregados nesses espaços.

Nesse âmbito escolarizador o conhecimento é tomado como algo que pode ser adquirido, somatizado, acumulado, avaliado. Nas instituições o sujeito passa a ser elemento indispensável para operacionalização da engrenagem escolar, submetendo crianças e jovens a um mundo burocratizado desde a tenra idade.

Em um universo não escolarizado, tem-se a chance de conhecer com vontade. Conhecer que diz da potência reativa das crianças e dos jovens, sem vincular essa existência a estratégias e dispositivos de captura que quantificam e qualificam traços, escritos e posturas. Chance de dar corpo e espaço para as relações humanas e o apoio mútuo, dispondo às vivências às aprendizagens emergentes dos encontros.

Periódico Horizontes - USF - Itatiba, SP - Brasil - e019054 


\section{Referências}

ALMEIDA, M. A. Memórias de um sargento de milícias. 25. ed. São Paulo: Ática, 1996.

BAKUNIN, M. Stato e anarchia. Milán: Feltrinelli, 1968.

CORRÊA, G. C. Educação, comunicação, anarquia: procedências da sociedade de controle no Brasil. São Paulo: Cortez, 2006.

FABBRI, L. Scuola e rivoluzione. Milán: Tipografia dell"Universitá Popolare, 1912.

FOUCAULT, M. Sobre a justiça popular. In: MACHADO, R. (Org.) (Trad.) Microfísica do poder. Rio de Janeiro: Edições Graal, 1979. p.39-68.

FERRER y GUÁRDIA, F. La escuela moderna. Madrid: La Malatesta, 2013.

GODWIN, W. Enquiry concerning political justice and its influence on morals and happiness. Baltimore: Penguin Books Ltd., 1976, E-book.

GONÇALVES, A. M. Francisco Ferrer y Guárdia: educação e a imprensa anarco-sindicalista - "A Plebe" (1917-1919). 2007. 132f. Dissertação (Mestrado em Educação) - Universidade Estadual de Ponta Grossa, Ponta Grossa, 2007.

GONÇALVES, A. M. A Trajetória e o pensamento educacional de Francisco Ferrer Y Guárdia. Cadernos de História da Educação, v.8, n.1. Disponível em:

http://www.seer.ufu.br/index.php/che/article/view/2274, 2009.

GORI, P. Conferenze politiche. Milán: Editrice Moderna, 1948.

GUSSINYER, P. S. Francesc Ferrer i Guàrdia: a escola moderna. In: SEBARROJA, J. C.; MURAD, F.; SILVA, V. B. M. Pedagogias do século XX. Trad. Fátima Murad. Porto Alegre: Ed. Artmed, 2003, p. 39-45.

ILLICH, I. Sociedade sem escolas. 7. ed. Petrópolis: Vozes, 1985. (Coleção Educação e Tempo Presente, 10)

ILLICH, I. Na ilha do alfabeto. In: ILLICH, I. et al. Educação e liberdade. Trad. Nelson Canabarro, São Paulo: Imaginário, 1990, p.11-35.

ILLICH, I. Sociedade desescolarizada. Porto Alegre: Deriva, 2007.

JACOTOT, J. Enseñanza universal. lengua materna. Trad. Pablo Ires. Buenos Aires: Cactus, 2008. ISBN 978-24075-2-0. 
KROPOTKIN, P. Anarquia. Enciclopédia Britânica, 1910. Disponível em: http://afoiceeomartelo.com.br/posfsa/Autores/Kropotkin,\%20Peter/KROPOTKIN,\%20P.\%20An arquismo\%20(enciclop\%C3\%A9dia\%20brit\%C3\%A2nica).pdf. Data de acesso: 22/09/2016.

KROPOTKIN, P. La scienza moderna e l'anarchia. Ginebra: Edizione do Risveglio, 1913.

MARSHALL, P. Demandando o impossível: uma história do anarquismo. Oakland, CA: PM Press. 2010.

NIETZSCHE, F. W. Aurora. Trad. Paulo C. de Souza. São Paulo: Companhia das Letras, 2004.

NIETZSCHE, F. W. A gaia ciência. Trad. Paulo César de Souza. 1. ed., São Paulo: Companhia das Letras, 2012.

PROUDHON, P. J. Da capacidade política das classes trabalhadoras. 1865. In: PROUDHON, P.J.; LAZARO, H. S.; GUIMARÃES, L. A. P. (Orgs.) O pensamento de Proudhon em educação. Rio de Janeiro: Intermezzo Editoral, 2015.

PROUDHON, P. J. Sistema das contradições econômicas ou filosofia da miséria. São Paulo: Ícone, 2003.

PROUDHON, P. J.; LAZARO, H. S.; GUIMARÃES, L. A. P. O pensamento de Proudhon em educação. Rio de Janeiro: Intermezzo Editoral, 2015.

RECLUS, E. O problema colonial. In: ANDRADE, M. C. Élisée Reclus. São Paulo: Editora Ática, 1985, p.109-130.

REIMER, E. A escola está morta: alternativas em educação. Trad. Tonie Tomson. 3.ed. Rio de Janeiro: Francisco Alves, 1983. (Série Educação em Questão).

SAINT-SIMON, C. Quelques idées soumises par M. de Saint-Simon à l'Assemblée générale de la Société d'instruction primaire. Paris: Imprimerie Cellot (brochure de 14 pages in- $8^{\circ}$, s/d), 1816.

STIRNER, M. O único e sua propriedade. Trad. João Barrento. São Paulo, SP: Martins Fontes, 2009.

TOLSTOI, L. Caracteristicas generales de la escuela. Revista de Jásnaja polyana, 1862.

TOLSTOI, L. La liberté dans L'école. Paris: Savine, 1888.

TOMASSI, T. Breviário del pensamiento educativo libertário. Madrid: Ediciones Madre Tierra, 1988. 
WOODCOCK, G. História das idéias e movimentos anarquistas: vol. I - a ideia. Porto Alegre: L\&PM, 2002.

Recebido em outubro de 2018.

Aprovado em outubro de 2019. 